\title{
The association of assistive mobility devices and social participation in people with spinal cord injuries
}

\author{
I-H Tsai ${ }^{1,2}$, DE Graves ${ }^{1,3}$ and C-H Lai ${ }^{2}$
}

Objective: We assumed that assistive technology in mobility devices (that is, wheelchairs with external power and driving modified vehicle (MV) with or without driving on wheelchair) may facilitate social participation for wheelchairs users who have spinal cord injuries (SCls). This study examined the relationship between mobility devices and social participation in this population.

Methods: We included 2986 individuals who had received initial rehabilitation at one of 18 regional centers of the Model Spinal Cord Injury System in the United States, had been interviewed between 2004 and 2010, and were wheelchair users (use a wheelchair $\geqslant 40 \mathrm{~h}$ per week and cannot ambulate 150 feet at home). We performed secondary panel-data analysis using a mixed-effect model on data from 3498 follow-up interviews. Participation (measured by the Craig Handicap Assessment and Reporting Technique-Short Form (CHART-SF) and employment status) and the use of wheelchair and MV were recorded.

Results: Among the participants, 33\% drove an MV, and 44\% used an external-powered wheelchair. The use of an MV was positively related to employment and CHART-SF score, regardless of driving directly or driving with a wheelchair. People who drove an MV were found to have approximately two more business associates to contact to once a month and $\sim 2$ additional days out of home per week compared with those without an MV. No significant association was shown between the type of wheelchair used and participation.

Conclusion: The use of an MV was found to be positively associated with social participation in an SCl population.

Spinal Cord (2014) 52, 209-215; doi:10.1038/sc.2013.178; published online 28 January 2014

Keywords: participation; integration; wheelchair; modified vehicle; spinal cord injury

\section{INTRODUCTION}

There are almost 12000 new cases of spinal cord injury (SCI) per year in the United States, primarily occurring in males and young adults. ${ }^{1}$ Only $\sim 1 \%$ of those suffering with SCI are discharged from the hospital without residual neurological impairment. ${ }^{1}$ Neurological impairment and long-term disability in persons with SCI results in inadequate social participation, including impaired fulfillment of social roles and maintenance of friendships and relationships. ${ }^{2}$ Achieving a sufficient level of mobility is essential for people with SCI to maintain participation in social activities. ${ }^{3-5}$ We would like to know whether the assistive technology in mobility devices (for example, external-powered wheelchairs and modified vehicle (MV)) facilitates the social participation for wheelchairs users who have SCIs.

A wheelchair is principally used for short distance mobility in the SCI population. It has been reported that one-third of wheelchair users employ an external-powered wheelchair (that is, power-assistive wheelchair or electric wheelchair). ${ }^{3,5}$ Laboratory experiments have suggested that wheelchair-assistive technologies may reduce the impact on the shoulder joint and cardiovascular system, reduce energy expenditure and increase the distance and speed of moving. ${ }^{6-9}$ However, few population studies have addressed how the assistive technology in wheelchair helps the social participation of the wheelchair user. A cross-sectional study evaluating the factors that are associated with productivity (that is, gainful employment, studies, homemaking, family activities, community organizations and leisure activities), which is similar to participation, found that the type of locomotion (that is, manual/powered wheelchair and walking) explained $3 \%$ of the variance of productivity, ${ }^{10}$ but the study did not compare various wheelchair types. Regarding the long-distance travel, the independence of transportation, particularly the ability to drive (which explained $7-14 \%$ of variance of productivity), has been reported to be related to productivity for people with SCI. ${ }^{10}$ In the United States, $81 \%$ of people with SCI did not use public transportation before their injury. ${ }^{11}$ Although the implementation of the Americans with Disabilities Act Title II increased paratransit services and fixed route services with disabled access, the availability and reliability of public transportation remains problematic in areas with limited public transportation. ${ }^{4,11,12}$ Therefore, regaining the ability to drive is important. Analysis of the National Spinal Cord Injury Database (NSCID) 2004-2006 has shown that driving an MV is related to higher level of participation and likelihood of employment, ${ }^{13}$ but no comparison was made between people driving MV directly and people driving on wheelchair. This study therefore aimed to evaluate the association between type of mobility devices use and social participation in wheelchair-using SCI individuals.

\section{MATERIALS AND METHODS}

The NSCID was established in 1970 and recruited individuals with traumatic SCI admitted to one of the regional centers in the Model Spinal Cord Injury System in the United States. ${ }^{14}$ By 2010, the NSCID had interviewed 27553 people with SCIs. ${ }^{14}$ Data were collected during the participants' initial hospitalization, post SCI, and follow-up interviews (either by phone, mail or 
in person) in the second year and every 5 years post injury. In this secondary panel-data analysis, we included wheelchair users (use wheelchair $\geqslant 40 \mathrm{~h}$ per week and unable to ambulate $\geqslant 150$ feet at home), age ranged from $18-90$ years, for which the following information was available: motor neurological level of injury (MNLI), ${ }^{1}$ American Spinal Cord Injury Association Impairment Scale (AIS), ${ }^{1}$ CHART-SF, ${ }^{15-17}$ employment status, the use of MV and wheelchair and other variables (see 'Covariates') known to be associated with participation. . $^{2,7,10,12,15,18-22}$ A total of 2986 participants from 18 regional centers were included with 3498 follow-up data applied for analysis (Figure 1).

\section{Exposure measurements}

The information on the use of mobility devices has been included in the NSCID since 2004. We categorized wheelchairs as manual or with external power (that is, power-assistive wheelchair, electric wheelchair and others). Participants using a MV were divided into 'drive an MV' and 'do not drive MV' groups. The 'drive an MV' group was further divided into 'drive directly' and 'drive on a wheelchair'. The 'do not drive MV' group was divided into 'own a MV but do not drive' and 'do not own a MV'.

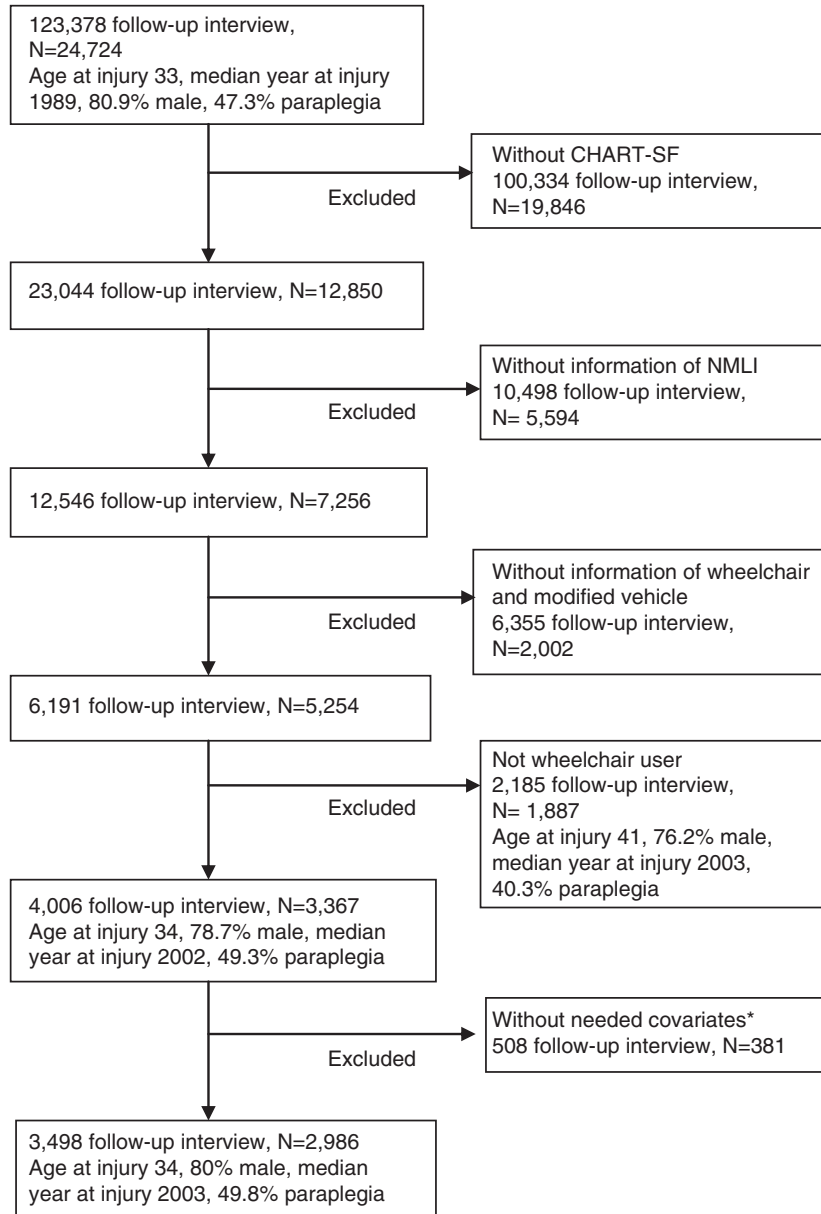

Abbreviations: CHART-SF: Craig Handicap Assessment and Reporting Technique-Short Form AIS: American Spinal Cord Injury Association Impairment Scale; MNLI: motor neurologic level of injury; Please refer to section Covariates for the detail.

Figure 1 Flowchart of the selection process from the National Spinal Cord Injury Database 2010. From 24724 participants who have follow-up interview, 3367 participants used a wheelchair for $\geqslant 40 \mathrm{~h}$ per week, could not walk 150 feet at home and had information available for mobilityassistive devices, Craig Handicap Assessment and Reporting TechniqueShort Form and employment during 2004-2010. After excluding data missing covariates needed for the multivariate analysis, the data from 2986 participants with 3498 copies of follow-up interviews were included.

\section{Outcome measurements}

Participations were measured using CHART-SF and employment rate. The CHART-SF questionere is a six-dimension scale that has been well validated as a measure of community participation of disabled individuals and has an estimated reliability of $80-95 \%$ for each dimension. ${ }^{15-17}$ The CHART-SF includes questions, such as, on the hours of paid assistance per day, days spent outside the home, or number of friends or business associates contacted to at least once a month. ${ }^{15-17}$ The score of each dimension (subscore) has a maximum of 100, with higher scores indicating a higher degree of participation. The NSCID had included entire CHART-SF from participants $\geqslant 18$ years since 2000 , but excluded the cognitive independence and economic self-sufficiency dimensions in 2006. Therefore, we summed the subscores of the remaining four dimensions (physical independence, mobility, occupation and social integration) to produce the total CHART score (CHART-t). Because clinical interpretation of this score is difficult, we also selected items (that is, days out of the house per week, number of friends and business associates contacted to at least once a month) from four dimensions to better reveal the participations that may be related to everyday mobility. The employment status ('employed or 'not employed') was also used to measure the participation in occupation. ${ }^{13,20,23}$

\section{Covariates}

Age, age at injury, time since injury, sex, level of education post injury, method of bladder management, level of pain and severity of neurological injury (MNLI and AIS), ${ }^{1}$ strength of upper limbs (grouped as 0-19, 20-39 and 40-50 in sum of manual muscle test score for key muscles of upper limbs $($ sMMTsUL $))^{1}$ and functional independence measurement $(\mathrm{FIM})^{1}$ were variables known associated to participation. ${ }^{1,2,7,10,12,15,18-22}$ Among those, age, severity of neurological injury and physical ability were known to be related to utilization of wheelchair and MV. ${ }^{3,19,24}$

\section{Data analysis}

The STATA 10 software was used for data analysis. Descriptive analyses showed the characteristics of the study population, with categorical variables expressed as percentages and continuous variables expressed as the mean and s.d. We created dummy variables for categorical variables regression analysis. The logistic regression analysis determined the factors associated with the use of mobility devices; and the univariate linear and logistic regression analysis examined the factors associated with CHART-t and employment status, respectively. All univariate analyses were conducted using each participant's most recent record of the period 2004-2010. For multivariate panel-data analysis on mobility devices and social participation, we applied the three-level generalized linear mixed-effect model to control for random effects of regional centers and participants. This analysis was applied based on the following assumptions: (1) participants registered to a particular regional center would experience similar weather, geography and infrastructure that might affect the choice of mobility device and participation; ${ }^{12,24}$ (2) each repetitive measurement for the same participant may yield similar results. We added variables that had a $P$-value $<0.2$ in the univariate analysis or had known to be related to participation and mobility devices selection with forward stepwise method in the model. By applying backward elimination, we maintained the covariate changing $10 \%$ of regression coefficient when it was removed or having $P<0.05$ by likelihood ratio test. ${ }^{25}$ We applied multivariate analysis with stratification of upper limbs strength because we considered that muscle strength is likely to better represent physical condition than isolate FIM, bladder management, MNLI or AIS. Age, years since injury, level of pain, gender and post-injury education were other variables included. Finally, the variance inflation factors were calculated for each model and were all $<10$. We set an alpha level of 0.05 for the hypothesis testing and reported $95 \%$ confidence intervals.

\section{Statement of ethics}

We certify that the study received ethics approval from the institutional review board of the University of Texas Health Science Center at Houston. All applicable institutional and governmental regulations concerning the use of human data were followed. 
Table 1 The characteristics of the study population and factors related to the use of power-featured wheelchair and modified vehicles $(N=2986)$

\begin{tabular}{|c|c|c|c|c|c|}
\hline Variables & N (\%) & $O R$ & $95 \% \mathrm{Cl}$ & $O R$ & $95 \% \mathrm{Cl}$ \\
\hline Current age (10 years) ${ }^{a}$ & $4.00(1.44)$ & $1.38^{*}$ & $1.31-1.45$ & $0.96^{*}$ & $0.91-1.01$ \\
\hline Age at injury $(10 \text { years })^{a}$ & $3.42(1.44)$ & $1.39 *$ & $1.32-1.46$ & $0.84^{*}$ & $0.8-0.89$ \\
\hline Year since injury ${ }^{a}$ & $5.75(0.08)$ & 1 & $0.98-1.01$ & $1.13^{*}$ & $1.11-1.15$ \\
\hline Male & $2362(79.13)$ & 1 & & 1 & \\
\hline Female & 623 (20.87) & $1.4^{*}$ & $1.25-1.73$ & $0.76^{*}$ & $0.64-0.91$ \\
\hline \multicolumn{6}{|l|}{ Education } \\
\hline$<$ High school & $454(15.2)$ & 1 & & 1 & \\
\hline$=$ High school & $1604(53.72)$ & 1.13 & $0.93-1.37$ & $2.34^{*}$ & $1.83-3.01$ \\
\hline In training & $266(8.91)$ & $0.63^{*}$ & $0.5-0.81$ & $2.56^{*}$ & $2.02-3.24$ \\
\hline Employed & $512(17.15)$ & $0.42^{*}$ & $0.35-0.52$ & $8.57^{*}$ & $7.01-10.48$ \\
\hline \multicolumn{6}{|l|}{ AIS } \\
\hline$A$ or $B$ & $2529(84.7)$ & 1 & & 1 & \\
\hline$C$ or $D$ & $457(15.3)$ & $1.56^{*}$ & $1.29-1.88$ & $0.62^{*}$ & $0.5-0.76$ \\
\hline \multicolumn{6}{|l|}{ MNLI } \\
\hline C1-C4 & 475 (15.91) & 1 & & 1 & \\
\hline C5-T1 & $1090(36.5)$ & $0.25^{*}$ & $0.19-0.33$ & $6.89^{*}$ & $4.62-10.28$ \\
\hline Below T1 & $1421(47.59)$ & $0.03^{*}$ & $0.02-0.04$ & $17.37^{*}$ & $11.73-25.71$ \\
\hline \multicolumn{6}{|l|}{ Mode of modified vehicle use } \\
\hline No access & 1252 (41.93) & 1 & & & \\
\hline Own but do not drive & $744(24.92)$ & $6.11^{*}$ & $5.03-7.41$ & & \\
\hline Driven on wheelchair & $209(7)$ & $2.96^{*}$ & $2.24-3.91$ & & \\
\hline Driven directly & $781(26.16)$ & $0.25^{*}$ & $0.2-0.31$ & & \\
\hline \multicolumn{6}{|l|}{ Bladder management } \\
\hline No assistive & $242(8.11)$ & 1 & & 1 & \\
\hline ICP & $1442(48.32)$ & $0.63^{*}$ & $0.48-0.82$ & $2.27^{*}$ & $1.7-3.02$ \\
\hline EUC & 319 (10.69) & 1.16 & $0.84-1.59$ & 1.37 & $0.97-1.93$ \\
\hline Catheter indwelling & $981(32.88)$ & $3.64^{*}$ & $2.76-4.79$ & $0.6^{*}$ & $0.44-0.82$ \\
\hline CHART (40 units) & $6.98(2.28)$ & $0.71^{*}$ & $0.69-0.74$ & $2.1^{*}$ & $1.98-2.21$ \\
\hline FIM (10 units) & $5.58(2.48)$ & $0.49^{*}$ & $0.47-0.51$ & $1.66^{*}$ & $1.6-1.73$ \\
\hline Pain ${ }^{a}$ & $4.38(2.99)$ & 1 & $0.98-1.03$ & $0.95^{*}$ & $0.93-0.98$ \\
\hline
\end{tabular}

Abbreviations: AIS, American Spinal Cord Injury Association Impairment Scale; CHART, Craig Handicap Assessment and Reporting Technique; CI, confidence interval; EUC, external urine collector; FIM, functional independence measure; ICP, intermittent catheterization program; MNLI, motor neurological level of injury; sMMTsUL, sum of manual muscle test score for upper limbs; powered featured wheelchair: PAWC, external-powered wheelchair or others other than manual wheelchair.

These people had their last interview during 2004-2010

${ }^{*} P<0.05$ by logistic regression model.

aMean and s.d. 


\section{RESULTS}

The characteristics of the study population are shown in Table 1 . The mean age of the study population was 40 years, with an average of 6 years post injury. The study population was mostly male $(78 \%)$ with one-third of the participants having been educated beyond high school level. Approximately half of the participants used external-powered wheelchairs and 35\% drove an MV. Approximately half of the participants had a sMMTsUL below $40(45 \%)$ and MNLI above T1 (52\%). One-fifth of the MV drivers drove on a wheelchair. The average CHART-t was 279 and $17 \%$ of participants was employed. Age, age at injury, being female, higher MNLI and having catheter indwelling in bladder were all positively related to use of an external-powered wheelchair but negatively related to driving an MV. Being employed, AIS A or B, upper limb strength and FIM scores were all negatively related to the use of an externalpowered wheelchair. Being employed, AIS A or B, upper limb strength, FIM scores and years since injury were positively related to driving an MV.

Table 2 Univariate regression ${ }^{\mathrm{a}}$ analysis for factors related to the CHART-t and being employed $(\boldsymbol{N}=2986)$

\begin{tabular}{|c|c|c|c|c|}
\hline \multirow[t]{3}{*}{ Variables } & \multicolumn{4}{|c|}{ Participation } \\
\hline & \multicolumn{2}{|c|}{ CHART-t } & \multicolumn{2}{|c|}{ Being employed } \\
\hline & $\beta$ & $95 \% \mathrm{Cl}$ & OR & $95 \% \mathrm{Cl}$ \\
\hline Current age (10 years) & $-15.43^{*}$ & $-17.64,-13.23$ & 0.94 & $0.88,1.00$ \\
\hline Age at injury (10 years) & $-18.74^{*}$ & $-20.91,-16.57$ & $0.84^{*}$ & $0.78,0.90$ \\
\hline Year since injury (year) & $3.30 *$ & $2.60,4.01$ & $1.10^{*}$ & $1.08,1.12$ \\
\hline Sex female (vs male) & -0.29 & $-8.33,7.76$ & 0.89 & $0.70,1.13$ \\
\hline \multicolumn{5}{|l|}{ Education } \\
\hline$=$ High school (vs < High school) & $29.74^{*}$ & $20.52,38.97$ & $3.71^{*}$ & $2.17,6.36$ \\
\hline$>$ High school (vs < High school) & $64.07 *$ & $54.13,74.02$ & $15.07 *$ & $8.85,25.67$ \\
\hline \multicolumn{5}{|l|}{ Employment } \\
\hline In training (vs unemployed) & $84.22^{*}$ & $74.30,94.14$ & & \\
\hline Employed (vs unemployed) & $117.33^{*}$ & $109.83,124.82$ & & \\
\hline AIS C or D (vs A or B) & $-29.40^{*}$ & $-38.42,-20.38$ & $0.59^{*}$ & $0.44,0.80$ \\
\hline \multicolumn{5}{|l|}{$M N L I$} \\
\hline C5-T1 (vs C1-C4) & $59.97^{*}$ & $50.92,69.02$ & $1.94^{*}$ & $1.34,2.80$ \\
\hline Below T1 (vs C1 -C4) & $100.53^{*}$ & $91.81,109.25$ & $3.15^{*}$ & $2.22,4.47$ \\
\hline \multicolumn{5}{|l|}{ Strength of upper limbs } \\
\hline sMMTsUL 20 -39 (vs 0-19) & 44.51 * & $35.28,53.73$ & $1.57^{*}$ & $1.13,2.20$ \\
\hline sMMTsUL $40-50$ (vs $0-19$ ) & $79.73 *$ & $72.63,86.83$ & $2.59 *$ & $2.00,3.36$ \\
\hline \multicolumn{5}{|l|}{ Type of wheelchair using } \\
\hline Power assistive (vs manual) & -22.04 & $-44.29,0.20$ & 1.14 & $0.62,2.10$ \\
\hline Electric (vs manual) & $-67.57^{*}$ & $-73.82,-61.32$ & $0.42^{*}$ & $0.34,0.52$ \\
\hline Others (vs manual) & -40.51 & $-81.11,0.09$ & 0.77 & $0.22,2.68$ \\
\hline \multicolumn{5}{|l|}{ Mode of modified vehicle use } \\
\hline Own but do not drive (vs no access) & -4.72 & $-11.77,2.32$ & $1.51^{*}$ & $1.07,2.12$ \\
\hline Drive on wheelchair (vs no access) & $78.40^{*}$ & $67.04,89.77$ & $7.68^{*}$ & $5.31,11.10$ \\
\hline Drive directly (vs no access) & $104.30 *$ & $97.37,111.24$ & $9.41^{*}$ & $7.17,12.35$ \\
\hline \multicolumn{5}{|l|}{ Bladder management } \\
\hline ICP (vs no assistance) & $31.28^{*}$ & $19.45,43.11$ & $2.13^{*}$ & $1.42,3.20$ \\
\hline EUC (vs no assistance) & -6.15 & $-20.66,8.37$ & 1.53 & $0.94,2.48$ \\
\hline Catheter indwelling (vs no assistance) & $-30.44^{*}$ & $-42.67,-18.22$ & 0.87 & $0.56,1.35$ \\
\hline CHART (40 units) & & & $2.96^{*}$ & $2.66,3.29$ \\
\hline FIM (10 units) & $2.14^{*}$ & $2.03,2.25$ & $1.30^{*}$ & $1.24,1.37$ \\
\hline Pain & $-4.74^{*}$ & $-5.56,-3.39$ & $0.91^{*}$ & $0.88,0.94$ \\
\hline
\end{tabular}


The association between participants' characteristics and participations are shown in Table 2. Age, age at injury, being female, complete motor injury, higher MNLI, using external-powered wheelchair, having catheter indwelling in bladder and pain were all negatively associated with CHART-t and likelihood of being employed. Years since injury, education beyond high school level, upper limb strength, driving an MV, using intermittent bladder catheterization and FIM score were positively related to CHART-t and the likelihood of being employed.

Table 3 shows the mixed-effect multivariate model of social participation with the mobility devices stratified by upper limb strength. Use of an MV was shown to be positively related to CHART-t score and employment, compared with not possessing or driving an MV. For participants with sMMTsUL $<20$, owning an MV has a significantly higher CHART-t $(\beta=20,95 \%$ confidence interval (CI) 12-32) and borderline significantly higher probability of employment (odds ratio $=3.14,95 \%$ CI: $1-10$ ), compared with those not owning an MV. The magnitude of association was similar in people driving an MV directly or on a wheelchair. The magnitude of association was less for those with sMMTsUL $\geqslant 20$, compared with those with sMMTsUL $<20$. The association between participation and the use of wheelchair was not significant. The estimation of mixed models was significantly different from regular linear or logistic regression models.

Table 4 shows the mixed-effect multivariate model of selected CHART items with mobility devices stratified by upper limb strength. Across all subgroups, participants who drove a MV had more days out of home per week and more friends/business associates to contact to compared with those not possessing or driving an MV. Participants who drove an MV had $\sim 2$ more days out of home per week, approximately two more business associates and approximately one additional friend contacted to at least once a month than people not possessing an MV. No association was noted between the use of wheelchair and CHART items. The estimation of mixed models was significantly different from regular linear or logistic regression models.

\section{DISCUSSION}

Previous study found that the type of locomotion explained 3\% of the variance of productivity, ${ }^{10}$ or showed that driving an $\mathrm{MV}$ is related to

Table 3 Multivariate generalized linear mixed-effect modela for participation and mobility devices with stratification of strength of upper limbs $(N=2986)$

Mobility devices

Participation

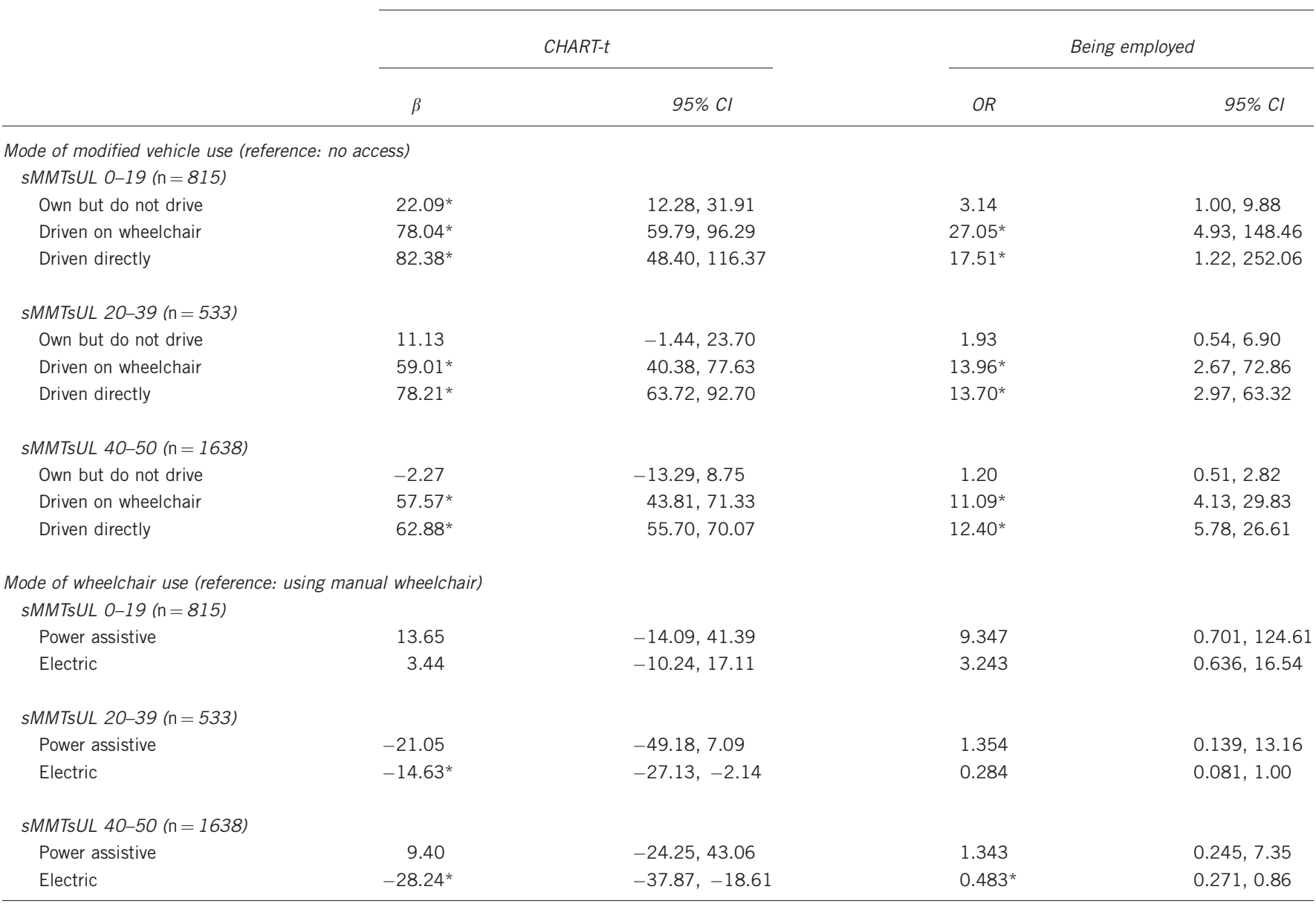

Abbreviations: CHART-t, total Craig Handicap Assessment and Reporting Technique; Cl, confidence interval; OR, odds ratio; sMMTsUL, sum of manual muscle test score for upper limbs, $\beta$, regression coefficient.

All generalized linear mixed models (linear regression for CHART-t and logistic regression for being employed) were adjusted with educational level, pain, sex, current age, year post injury and were significantly different from linear or logistic regression by likelihood ratio test.

significantly
$* P<0.05$

${ }^{*} \mathrm{P}<\mathrm{M}$ ixed-effect linear regression model for CHART-t and logistic regression model for employment with addressing random effect of region and person. 
Table 4 Multivariate linear mixed-effect model on selected CHART items ${ }^{\mathrm{a}}$ and mobility devices with stratification of strength of upper limbs $(N=2986)$

Mobility devices

Selected CHART items

\begin{tabular}{|c|c|c|c|c|c|c|}
\hline & \multicolumn{2}{|c|}{ Days out of the house per week } & \multicolumn{2}{|c|}{$\begin{array}{l}\text { Number of friends contacted } \\
\text { at least once a month }\end{array}$} & \multicolumn{2}{|c|}{$\begin{array}{c}\text { Number of business associates contacted } \\
\text { at least once a month }\end{array}$} \\
\hline & $\beta$ & $95 \% \mathrm{Cl}$ & $\beta$ & $95 \% \mathrm{Cl}$ & $\beta$ & $95 \% \mathrm{Cl}$ \\
\hline \multicolumn{7}{|c|}{$\begin{array}{l}\text { How modified vehicle using (reference: no access) } \\
\quad \text { sMMTSUL 0-19 }(\mathrm{n}=815)\end{array}$} \\
\hline Own but do not drive & $0.60^{*}$ & $0.30,0.91$ & $0.31^{*}$ & $0.08,0.54$ & $1.11^{*}$ & $0.62,1.59$ \\
\hline Driven on WC & $2.48^{*}$ & $1.91,3.05$ & $0.66^{*}$ & $0.24,1.09$ & $2.33^{*}$ & $1.42,3.24$ \\
\hline Driven directly & 1.06 & $-0.04,2.16$ & 0.69 & $-0.13,1.52$ & $2.86^{*}$ & $1.13,4.58$ \\
\hline \multicolumn{7}{|c|}{ sMMTsUL 20-39 $(\mathrm{n}=533)$} \\
\hline Own but do not drive & $0.48^{*}$ & $0.07,0.88$ & $0.41^{*}$ & $0.11,0.72$ & -0.13 & $-0.81,0.56$ \\
\hline Driven on WC & $2.36^{*}$ & $1.75,2.96$ & $0.57^{*}$ & $0.11,1.02$ & $1.55^{*}$ & $0.52,2.57$ \\
\hline Driven directly & $2.08^{*}$ & $1.62,2.55$ & $0.88^{*}$ & $0.53,1.23$ & $1.77^{*}$ & $0.98,2.56$ \\
\hline \multicolumn{7}{|c|}{ sMMTsUL 40-50 $(\mathrm{n}=1638)$} \\
\hline Own but do not drive & 0.05 & $-0.29,0.40$ & 0.01 & $-0.25,0.28$ & -0.27 & $-0.84,0.30$ \\
\hline Driven on WC & $2.00^{*}$ & $1.58,2.42$ & $0.65^{*}$ & $0.32,0.98$ & $1.87^{*}$ & $1.16,2.58$ \\
\hline Driven directly & $1.85^{*}$ & $1.63,2.07$ & $0.58^{*}$ & $0.41,0.75$ & $1.84^{*}$ & $1.47,2.21$ \\
\hline \multicolumn{7}{|c|}{ Type of wheelchair using (reference: use manual wheelchair) } \\
\hline Power assistive & $0.90^{*}$ & $0.00,1.81$ & 0.11 & $-0.55,0.77$ & 0.68 & $-0.72,2.09$ \\
\hline Electric & 0.08 & $-0.35,0.51$ & 0.01 & $-0.30,0.32$ & -0.08 & $-0.76,0.59$ \\
\hline \multicolumn{7}{|c|}{ sMMTsUL 20-39 $(\mathrm{n}=533)$} \\
\hline Power assistive & 0.11 & $-0.87,1.09$ & 0.26 & $-0.43,0.95$ & 0.13 & $-1.44,1.70$ \\
\hline Electric & 0.23 & $-0.17,0.62$ & -0.01 & $-0.29,0.27$ & -0.55 & $-1.18,0.07$ \\
\hline \multicolumn{7}{|c|}{ sMMTsUL 40-50 $(\mathrm{n}=1638)$} \\
\hline Power assistive & 0.32 & $-0.74,1.39$ & 0.13 & $-0.64,0.90$ & 1.50 & $-0.21,3.20$ \\
\hline Electric & -0.22 & $-0.52,0.08$ & $-0.37^{a}$ & $-0.58,-0.15$ & $-0.66^{*}$ & $-1.14,-0.19$ \\
\hline
\end{tabular}

Abbreviations: CHART-t, total Craig Handicap Assessment and Reporting Technique; Cl, confidence interval; sMMTsUL, sum of manual muscle test score for upper limbs; WC, wheelchair; $\beta$, regression coefficient.

All mixed linear model were adjusted with educational level, pain, sex, current age, year post injury and were significantly different from linear regression by likelihood ratio test.

$* P<0.05$.

aMixed-effect linear regression model for each CHART items (days out of the house per week, number of friends contacted per month, and number of business contacts per month) with addressing random effect of region and person.

a higher level of participation and likelihood of employment. ${ }^{13}$ One study of 192 SCI participants, had shown no association between the means of mobility (use wheelchair only, non-functional ambulation, and functional ambulation) and employment status. ${ }^{26}$ Nevertheless, none of these studies compared the different types of wheelchair or the way of driving MV. We studied each specific type of mobility-assistive devices. We found that regardless of the level of muscle strength of the upper limbs, driving an MV directly or driving on a wheelchair was positively associated with participation. The results regarding wheelchairs were not significant. We suggested that coexisting medical conditions (for example, spasticity, pressure sore, malnutrition and cardiopulmonary dysfunction) other than the factors that we had controlled may affect participation and choice of the type of wheelchairs as well as confounded the results. $1,10,20$

Whiteneck et al. ${ }^{22,27}$ had used 75 as a cut-off point for CHART subscale during analysis. To avoid loss of information, we analyzed the total score. We also analyzed the CHART-SF items to produce easily interpretable results. As the CHART-t score, the selected
CHART-SF items had a similar association to the use of mobility devices (Table 4).

In contrast to previous studies addressing mobility devices in the SCI population, we specifically focused on wheelchair users who use a wheelchair $\geqslant 40 \mathrm{~h}$ per week and are unable to ambulate $\geqslant 150$ feet at home. We assumed that the benefit of using an external-powered wheelchair and driving an MV was greater in this subgroup than in people who ambulate well or are bed-ridden..$^{10,13,26}$ In fact, we found a greater magnitude of association between driving $\mathrm{MV}$ and participation (Table 3) than reported by Norweg et al. ${ }^{13}$; this finding may be due to our target population selection. We also found that the magnitude of association between driving an MV and participation was stronger than that of college education and participation in the multivariate analysis. Interestingly, college education has been reported to be significantly related to higher levels of social participation. ${ }^{20}$ However, as only $33 \%$ of our study population drove an MV, enhancing the availability and affordability of MV may be needed. ${ }^{11}$ 
The NSCID provided a large sample size to increase the power and variables available to control the potential confounders. In our analysis, studying only wheelchair users resulted in larger effect size compared with previous studies. The three-level generalized linear mixed-effect model for multivariate analysis allowed for the control of random effects of regional centers and participants. However, limitations exist in our study. Fifteen percent of data were the second repeated measurements, but the cohort elements were not controlled. The information bias may occur as CHART-SF is a self-report questionnaire, only four out of six CHART-SF dimensions were used to determine participation, and employment quality (for example, full-time, part-time or intermittent) is unknown here. ${ }^{19,20}$ Cognitive independence and financial support may enable participation, securing employment or purchasing an $\mathrm{MV}$, but we had no related data. The coexisting medical conditions were not controlled in the analysis due to a lack of information. The definition of wheelchair user was arbitrary. The generalizability of this study was limited because we only included wheelchair users who had traumatic SCI. Causality could not be demonstrated because of the lack of a temporal relationship between the use of mobility devices and the participation. The interaction between the use of mobility devices and covariates was not studied. Nonetheless, power-assistive wheelchair or MV with driving on a wheelchair was used by few participants, so precise estimation cannot be produced.

\section{CONCLUSIONS}

Either driving an MV directly or on a wheelchair was positively associated with participation in wheelchair-using SCI individuals, regardless of the strength of their upper limbs. No association was observed between the type of wheelchair used and participation. The inclusion of sufficient participants who use each of the particular types of mobility devices is needed for further studies.

\section{DATA ARCHIVING}

There were no data to deposit.

\section{CONFLICT OF INTEREST}

The authors declare no conflict of interest.

\section{DISCLAIMER}

We certify that no party having a direct interest in the results of the research supporting this article has or will confer a benefit on us or on any organization with which we are associated.

1 Bryce TN, Ragnarsson KT, Stein AB, Biering-Sorensen F. Spinal cord injury. In: Braddom RL (eds.) Physical Medicine \& Rehabilitation, 4th edn, Saunders Elsevier: USA, 2011.

2 Charlifue S, Gerhart K. Community integration in spinal cord injury of long duration. Neurorehabilitation 2004; 19: 91-101.

3 Biering-Sorensen F, Hansen RB, Biering-Sorensen J. Mobility aids and transport possibilities 10-45 years after spinal cord injury. Spinal Cord 2004; 42: 699-706.
4 National Council on Disability. Nation summit on disability policy 2010: Working paper. National Council on Disability: Washington, DC, 2009.

5 Rushton PW, Miller WC, Mortenson WB, Garden J. Satisfaction with participation using a manual wheelchair among individuals with spinal cord injury. Spinal Cord 2010; 48: 691-696.

6 Ding D, Souza A, Cooper RA, Fitzgerald SG, Cooper R, Kelleher A et al. A preliminary study on the impact of pushrim-activated power-assist wheelchairs among individuals with tetraplegia. Am J Phys Med Rehabil 2008; 87: 821-829.

7 Kennedy P, Lude P, Taylor N. Quality of life, social participation, appraisals and coping post spinal cord injury: A review of four community samples. Spinal Cord 2006; 44: 95-105.

8 Simpson RC, LoPresti EF, Cooper RA. How many people would benefit from a smart wheelchair? J Rehabil Res Dev 2008 01; 45: 53-71.

9 Ambrosio F, Boninger ML, Fitzgerald SG, Hubbard SL, Schwid SR, Cooper RA. Comparison of mobility device delivery within department of veterans affairs for individuals with multiple sclerosis versus spinal cord injury. J Rehabil Res Dev 2007 09; 44: 693-702.

10 Noreau L, Dion SA, Vachon J, Gervais M, Laramee MT. Productivity outcomes of individuals with spinal cord injury. Spinal Cord 1999; 37: 730-736.

11 Wehman P, Wilson K, Targett P, West M, Bricout J, McKinley W. Removing transportation barriers for persons with spinal cord injuries: an ongoing challenge to community reintegration. J Vocation Rehabil 1999 08; 13: 21.

12 Sekaran P, Vijayakumari F, Hariharan R, Zachariah K, Joseph SE, Kumar RK. Community reintegration of spinal cord-injured patients in rural south india. Spinal Cord 2010; 48: 628-632.

13 Norweg A, Jette AM, Houlihan B, Ni P, Boninger ML. Patterns, predictors, and associated benefits of driving a modified vehicle after spinal cord injury: Findings from the national spinal cord injury model systems. Arch Phys Med Rehabil 2011; 92: 477-483.

142010 NSCISC Annual Statistical Report - Complete Public Version. National Spinal Cord Injury Statistical Center: Birmingham, Alabama. Available at https://www.nscisc. uab.edu/PublicDocuments/reports/pdf/2010\%20NSCISC\%20Annual\%20Statistical\% 20Report\%20-\%20Complete\%20Public\%20Version.pdf. (accessed 24 February 2012).

15 Hall KM, Dijkers M, Whiteneck G, Brooks CA, Krause JS. The Craig handicap assessment and reporting technique (CHART): Metric properties and scoring. Top Spinal Cord Inj Rehabil 1998; 4: 16-30.

16 De Wolf A, Lane-Brown A, Tate RL, Middleton J, Cameron ID. Measuring community integration after spinal cord injury: Validation of the Sydney psychosocial reintegration scale and community integration measure. Qual Life Res 2010; 19: 1185-1193.

17 Whiteneck GG, Gerhart K, Mellick D. Guide for Use of CHART: Craig Handicap Assessment and Reporting Technique. Craig Hospital: Englewood, CO, 1992.

18 Jensen MP, Hoffman AJ, Cardenas DD. Chronic pain in individuals with spinal cord injury: A survey and longitudinal study. Spinal Cord 2005; 43: 704-712.

19 Franceschini M, Di Clemente B, Rampello A, Nora M, Spizzichino L. Longitudinal outcome 6 years after spinal cord injury. Spinal Cord 2003; 41: 280-285.

20 Lidal IB, Huynh TK, Biering-Sorensen F. Return to work following spinal cord injury: a review. Disabil Rehabil 2007; 29: 1341-1375.

21 Conroy L, McKenna K. Vocational outcome following spinal cord injury. Spinal Cord 1999; 37: 624-633.

22 Whiteneck GG, Brooks CA, Harrison-Felix C, Gerhart K. Exploring the Relationship Between Participation and Environmental Factors: A Look at Three Studies using the Craig Handicap Assessment and Reporting Technique (CHART) and the Craig Hospital Inventory of Environmental Factors (CHIEF). Craig Hospital: Englewood, CO, 2004.

23 Ville I. Biographical work and returning to employment following a spinal cord injury. Sociol Health IIIn 2005; 27: 324-350.

24 Dijkers MP, Yavuzer G, Ergin S, Weitzenkamp D, Whiteneck GG. A tale of two countries: environmental impacts on social participation after spinal cord injury. Spinal Cord 2002; 40: 351-362.

25 Kleinbaum D, Kupper L, Muller K. Applied regression analysis and other multivariable methods, 2nd edn Duxbury Press: Belmont, CA, 1988.

26 Kurtaran A, Akbal A, Ersöz M, Selçuk B, Yalçın E, Akyüz M. Occupation in spinal cord injury patients in turkey. Spinal Cord 2009; 47: 709-712.

27 Whiteneck G, Meade MA, Dijkers M, Tate DG, Bushnik T, Forchheimer MB. Environmental factors and their role in participation and life satisfaction after spinal cord injury. Arch Phys Med Rehabil 2004; 85: 1793-1803. 